\title{
Correction factors for oxygen and flow-rate effects on neonatal Fleisch and Lilly pneumotachometers
}

\author{
Yvonne Snepvangers, MD; Peter de Winter, PhD; Huibert Burger, PhD; Hens A. Brouwers, PhD; \\ Jan M. Bogaard, PhD; Kors van der Ent, PhD
}

Objective: To assess the effects of different oxygen concentrations and flow rates on the measurement errors of neonatal pneumotachometers in heated and unheated situations and to develop correction factors to correct for these effects.

Design: Prospective laboratory study.

Setting: Outpatient clinic with equipment in a standardized setting.

Subjects: Neonatal pneumotachometers.

Interventions: In standardized conditions, the tested pneumotachometer was calibrated at a flow rate of $3 \mathrm{~L} / \mathrm{min}$ with $60 \%$ oxygen and was set in series with a closed spirometer system being used as a reference. Different air-flow levels (1-9 L/min) and oxygen concentrations (21-100\%) were infused into the closed system with the pneumotachometer and spirometer.

Measurements and Main Results: The pneumotachometers were significantly affected by changing oxygen concentrations ( $p$ $<.01)$ and increasing flow rates $(p<.01)$, increasing the actually measured flow rate. Correction factors, developed by multiple regression analysis, significantly reduced the overall maximum errors of the pneumotachometers from -1.1 to $0.6 \mathrm{~L} / \mathrm{min}$ to -0.5 to $0.4 \mathrm{~L} / \mathrm{min}$.

Conclusions: The effects of changes in oxygen concentrations and flow rates on neonatal pneumotachometers could be considerably decreased by the use of correction factors such as were calculated in this study. This will preclude frequent calibration procedures with actual flow and oxygen levels during changes in experimental settings. (Pediatr Crit Care Med 2003; 4:227-232)

KEY WORDS: newborn infant; measurement error; lung function; Fleisch pneumotachometer; Lilly pneumotachometer

\section{I}

$\mathrm{n}$ research and in clinical practice, accurate measurements of respiratory gas flow rates are important. Pneumotachometers are used in setups for estimating lung volumes, respiratory system compliance, and resistance. Pneumotachometers can be based on several principles, such as linear resistive pneumotachometers, turbine flowmeters, thermal devices, ultrasonic flowmeters, polyvinylidene fluoride piezoelectric film flowmeters, nonlinear differential pressure-based transducers, linear differential pressure devices, and flow plethysmography (1). Because the dead space of pneumotachometers has been sufficiently reduced, they can be used in neonates. There are, however,

From the Departments of Pediatric Pulmonology (YS, KvdE), Neonatology (HAB), and the Julius Center for Health Sciences and Primary Care (HB), University Medical Center Utrecht, Utrecht, The Netherlands; the Department of Pediatrics, Spaarne Hospital, Haarlem, The Netherlands (PdW); and the Department of Pulmonary Diseases, Pathophysiological Laboratory, University Hospital Dijkzigt, Rotterdam, The Netherlands (JMB).

Copyright $\odot 2003$ by the Society of Critical Care Medicine and the World Federation of Pediatric Intensive and Critical Care Societies

DOI: 10.1097/01.PCC.0000059334.04333.1B more specific conditions to be taken into account during lung function testing in neonates, especially when they are mechanically ventilated. According to Hagen-Poiseuille's law, changes in physical characteristics of a respiratory gas (composition, temperature, relative humidity, and pressure) (2) directly affect pneumotachometer flow measurements (3-14).

$$
\begin{aligned}
& \mathrm{p}_{\mathrm{D}}=(8 \cdot L \cdot \eta \cdot v) /\left(\pi \cdot r^{4}\right) \\
& \mathrm{p}_{\mathrm{D}}=\text { decrease in pressure } \\
& L=\text { length of tube over which the } \\
& \text { pressure decrease is measured } \\
& \eta=\text { viscosity of gas } \\
& v=\text { velocity } \\
& r=\text { radius of tube over which the pres- } \\
& \text { sure decrease is measured }
\end{aligned}
$$

In addition, turbulence (15), the geometry of the tubes connecting the pneumotachometers (16), and the dimensions of the resistive element (15) influence flow recordings by pneumotachometers.

In experimental settings at a neonatal intensive care unit, $\mathrm{H}_{2} \mathrm{O}$ can accumulate on the resistive element of pneumotachometers, increasing resistance and causing turbulence, leading to measurement errors. Heating of the pneumota- chometer diminishes this effect. In the neonatal intensive care unit, flow rates and oxygen concentrations are often changed, leading to a varied accuracy of flow signals.

In recently developed neonatal ventilators, algorithms are incorporated to reduce the measurement error of their pneumotachometers. However, most neonatal ventilators (Stephanie and Dräger, among other companies) only include corrections for body temperature and pressure saturated with $\mathrm{H}_{2} \mathrm{O}$ vapor. The Viasys Avea and the VIP Bird neonatal and pediatric ventilators also correct for altitude (barometric pressure). However, to the best of our knowledge, no correction is made for actual oxygen concentration and flow rate.

We investigated the accuracy of the two most frequently used neonatal pneumotachometers (17) to measure lung function in experimental settings. Both are based on the linear resistive principle: a Fleisch-type pneumotachometer (consisting of parallel capillary tubes) (5) and a Lilly-type pneumotachometer (containing a fine wire mesh screen) (8). We studied measurement errors secondary to changing measurement conditions (e.g., flow rate, oxygen concentration, and 
heating of the devices). Correction factors were calculated to prevent the need for frequent calibration procedures at actual flow rates and oxygen concentrations.

\section{MATERIAL AND METHODS}

A Lilly pneumotachometer (8410A, Hans Rudolph, Kansas City, MO; linear range, 0-10 $\mathrm{L} / \mathrm{min})$ and a Fleisch pneumotachometer (00, General Medical, Erie, PA; linear range, 0-9 $\mathrm{L} / \mathrm{min}$ ) were tested. Pressure differences across the resistive element of both pneumotachometers were measured with a differential pressure transducer (163PC01D75, Honeywell, Morristown, $\mathrm{NJ}$ ).

Air and oxygen from the hospital circuit were mixed with an oxygen-air mixer (961 Siemens-Elema, Siemens, The Hague, The Netherlands), and flow rates were roughly set by a rotameter (air 0-15 L/min, Medec, Aalst, Belgium) (Fig. 1).

The oxygen concentration (at $30 \mathrm{~cm}$ before the pneumotachometer) and the temperature (at $80 \mathrm{~cm}$ after the pneumotachometer) inside the system were recorded by an oxygen meter (Teledyne TED 60T, Teledyne Brown Engineering, Huntsville, AL) and a thermometer (Fluke $51 \mathrm{~K} / \mathrm{J}$ thermometer, Fluke Nederland B.V., Eindhoven, The Netherlands), respectively. A 10-L rolling seal spirometer (Masterscreen-FRC Jaeger complete system, Erich Jaeger GmbH, Hoechberg, Germany) was used as a standard for volume against time. Connections between different parts of the equipment were formed by ribbed rubber tubes with an inner diameter of $2 \mathrm{~cm}$ and an outer diamtachometer, and the standard ribbed tubes belonging to the spirometer with an inner diameter of $3.0 \mathrm{~cm}$ and an outer diameter of $3.2 \mathrm{~cm}$ connected the former tubes from the point of temperature assessment to the spirometer. Flow signals from the pneumotachometers were processed by computer, using the software package RASP (Respiratory Analysis System Program, Physio Logic, High Clere, UK).

We calibrated the pneumotachometer system at an oxygen concentration of $60 \%$ to keep the maximum error, expected to be eter of $2.9 \mathrm{~cm}$ before and after the pneumo-

caused by the most extreme oxygen concentrations, as small as possible. Flow calibration was performed at zero flow and at a maximum of $3 \mathrm{~L} / \mathrm{min}$ according to the spirometer. Because flow rates measured by the spirometer can only be determined afterward, all measured values were multiplied with a new calibration factor determined afterward at 3 $\mathrm{L} / \mathrm{min}$ and $60 \%$ oxygen. This calibration procedure was performed for each measurement session separately.

At the start of the measurements, an oxygen concentration of $21 \%$ and a steady-flow rate of about $1 \mathrm{~L} / \mathrm{min}$ (according to the spirometer) was used. We repeated the same procedure at an oxygen concentration of $21 \%$ and a steady-flow rate of $2 \mathrm{~L} / \mathrm{min}$, followed by 3,4 , 6 , and $9 \mathrm{~L} / \mathrm{min}$. Afterward, we tested the other oxygen concentrations of $30 \%, 40 \%, 50 \%$, $60 \%, 70 \%, 80 \%, 90 \%$, and $100 \%$ at the same steady-flow rates. We repeated half the session (i.e., the same measurement procedures) in the opposite order at $100 \%, 80 \%, 60 \%, 40 \%$, and $21 \%$ oxygen every time at $1,3,6$, and 9 $\mathrm{L} / \mathrm{min}$.

The complete procedure was performed for each pneumotachometer (i.e., the Lilly and the Fleisch pneumotachometer) heated and unheated. Recordings during every measurement were continued until the spirometer with a volume of $10 \mathrm{~L}$ was completely filled, except at a flow rate of $1 \mathrm{~L} / \mathrm{min}$ in which a mean maximum total volume of $6 \mathrm{~L}$ was achieved. No lower volumes were accepted to prevent measurement errors due to a potential inaccuracy of the spirometer. Before and after each measurement procedure, calibration settings were checked with a precision syringe of $50 \mathrm{~mL}$ independently from the spirometer. When this check revealed an error of $>2.5 \%$, the whole measurement procedure was repeated.

Paired-samples $t$-tests were performed to estimate significant differences of the measurement errors between calibration level and the lowest and highest oxygen concentrations and flow rates. Bonferroni's correction for multiple comparisons was performed. Multiple regression analyses were used to derive correction equations for each pneumotachometer. We used a stepwise forward regression

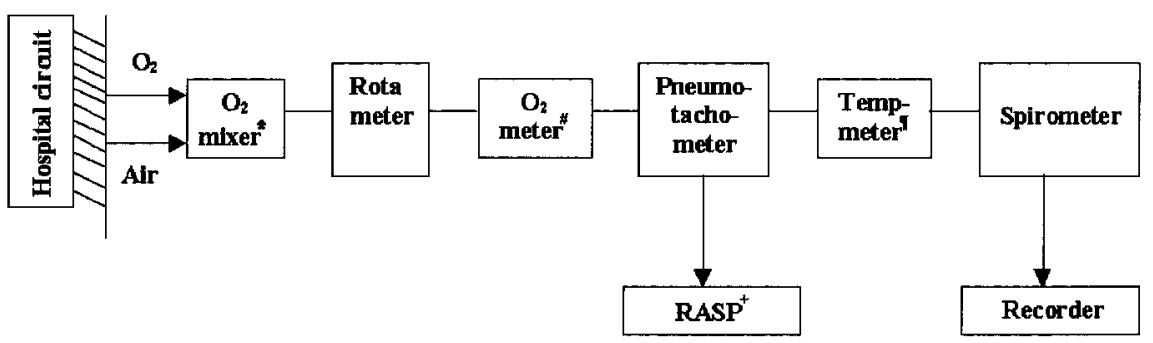

Figure 1. Schematic view of the experimental setting during the measurements. *, oxygen-air mixer; \#, oxygen concentration meter; I, thermometer; ${ }^{+}$, RASP, Respiratory Analysis System Program. technique with the reference flow (i.e., the flow recorded by the spirometer) as the dependent variable. The flow measured by the pneumotachometer, its product term with the oxygen concentration, and its square were included as independent variables. Variables were added on the basis of statistical significance $(p<.05)$ or when they substantially improved the fit of the model, according to the distribution of the residuals left.

To enable comparison between pneumotachometers, data were presented as relative measurement errors calculated from the regression equations. This means that the differences between the flow rates measured by the pneumotachometer and the calculated spirometer flow rates (dependent variable in the regression equation) after entering the pneumotachometer flows in the equations were presented. These differences were divided by the spirometer values and expressed as percentages. Because variances explained by the regression equations were very high $\left(R^{2}>\right.$ .99 ), no important deviations from the real measured data were to be expected.

To test the improvement due to the use of the correction factors following from the regression equations, Bland and Altman plots (18) were used in which the differences between the spirometer and pneumotachometer were plotted against the mean of their flow rates. The paired-samples Student's $t$-test was again used to estimate any significant improvements due to the use of these correction factors. Polynomials of different pneumotachometer flow errors relative to spirometer flow were calculated with the multiple regression equations using arbitrary oxygen concentrations and flow rates. The Statistical Product and Service Solutions 10.0 (SPSS, Chicago, IL, USA) for Windows was used for the statistical calculations.

\section{RESULTS}

The temperature measured inside the closed circuit at $80 \mathrm{~cm}$ after the pneumotachometer did not change by $>1.3^{\circ} \mathrm{C}$ (ranges for each experiment: 21.9-23.2, 20.2-21.1, 21.1-21.7, 20.3-21.4) for the unheated pneumotachometers and did not change by $>2.4^{\circ} \mathrm{C}$ (ranges for each experiment: 20.7-23.1, 20.6-21.7, 22.123.1, 21.3-23.1) for the heated pneumotachometers within each experiment. Changes of barometric pressure and humidity during the measurement procedures were not present or were very small, reaching maximum values of 0.2 $\mathrm{kPa}$ and $4 \%$, respectively.

Considerable effects of oxygen concentration, shown in Figure 2, were un- 
derlined by the relative error being significantly different at $21 \%$ and $100 \%$ oxygen (at $3 \mathrm{~L} / \mathrm{min}$ ) compared with calibration level $(60 \%$ oxygen at $3 \mathrm{~L} / \mathrm{min})$ in all pneumotachometers $(p<.02)$. All pneumotachometers showed a comparable increase of the relative measurement error at rising oxygen concentrations, the most prominent for the unheated Lilly pneumotachometer. However, differences between pneumotachometers were small.

Compared with calibration level (3 $\mathrm{L} / \mathrm{min}$ at $60 \%$ oxygen), the measurement errors were significantly different at 1 $\mathrm{L} / \mathrm{min}$ and $9 \mathrm{~L} / \mathrm{min}$ at $60 \%$ oxygen in all pneumotachometers $(p<.02)$ (Fig. 3). An increasing measurement error became apparent in all pneumotachometers above the calibration flow rate. The relative measurement error also increased at lower flow rates. Again, differences between pneumotachometers were relatively small.

Multiple regression analyses yielded correction equations for each pneumotachometer (Table 1). With these regression equations, a corrected flow could be calculated from the measured flow at different levels of oxygen concentration and flow rate. As illustrated in Table 2, correction of the measured values with pneumotachometers resulted in a significant decrease of the measurement errors $(p<.03)$ in all pneumotachometers. Before correction, a mean measurement er- ror varied between -0.13 and -0.36 $\mathrm{L} / \mathrm{min}$, depending on the pneumotachometer tested. After correction, this was significantly reduced to -0.01 and $-0.04 \mathrm{~L} / \mathrm{min}$. Limits of agreement, corresponding with $2 \mathrm{SD}$ of the differences between the pneumotachometer and spirometer, even exceeded $1 \mathrm{~L} / \mathrm{min}$ in some cases, whereas these limits remained at $<0.40 \mathrm{~L} / \mathrm{min}$ after correction. Maximal error ranges showed a comparable pattern.

To avoid the use of these complex correction equations in practice, we calculated polynomials to estimate the relative measurement errors at arbitrary oxygen concentrations and flow rates.

The heated Fleisch pneumotachometer showed the most dispersed polynomials in the horizontal direction, indicating that the relative measurement error did not increase as fast at rising flow levels as it did in the heated and unheated Lilly pneumotachometers and the unheated Fleisch pneumotachometer. The heated Fleisch curve in Figure 3 also appeared to be the flattest. Judging by the dispersion of the curves in Figure 4, in the vertical direction, the increase of the measurement errors based on a rise in oxygen concentration was most obvious in the unheated Lilly pneumotachometer and least obvious in the unheated Fleisch pneumotachometer. This is also demonstrated in Figure 2.

\section{DISCUSSION}

Both the Fleisch and Lilly pneumotachometers were significantly affected by increasing oxygen concentrations from $21 \%$ to $100 \%$ and increasing flow rates from 1 to $9 \mathrm{~L} / \mathrm{min}$, increasing the actually measured flow rate in the heated and in the unheated situation. Multiple regression analysis yielded correction factors to correct for these effects, resulting in a significantly improved accuracy of the flow measurements in almost all pneumotachometers. This means that after a calibration at 0 and $3 \mathrm{~L} / \mathrm{min}$ and $60 \%$ oxygen and correction for the influences of oxygen and flow rate, reliable flow measurements can be achieved in the appropriate flow range and at all oxygen concentrations with these neonatal pneumotachometers.

Although linear-resistance pneumotachometers are supposed to be used heated to avoid $\mathrm{H}_{2} \mathrm{O}$ accumulation, we tested them unheated as well. In practice, sometimes, unheated probes are used. Therefore, it would be interesting to correct for measurement errors caused by differences in heating, assuming that no detectable $\mathrm{H}_{2} \mathrm{O}$ accumulation had occurred in the unheated situation. Our results confirmed that when heated pneumotachometers were used, the error caused by flow rates, but not by oxygen concentrations, was less compared with when they were tested unheated. How-

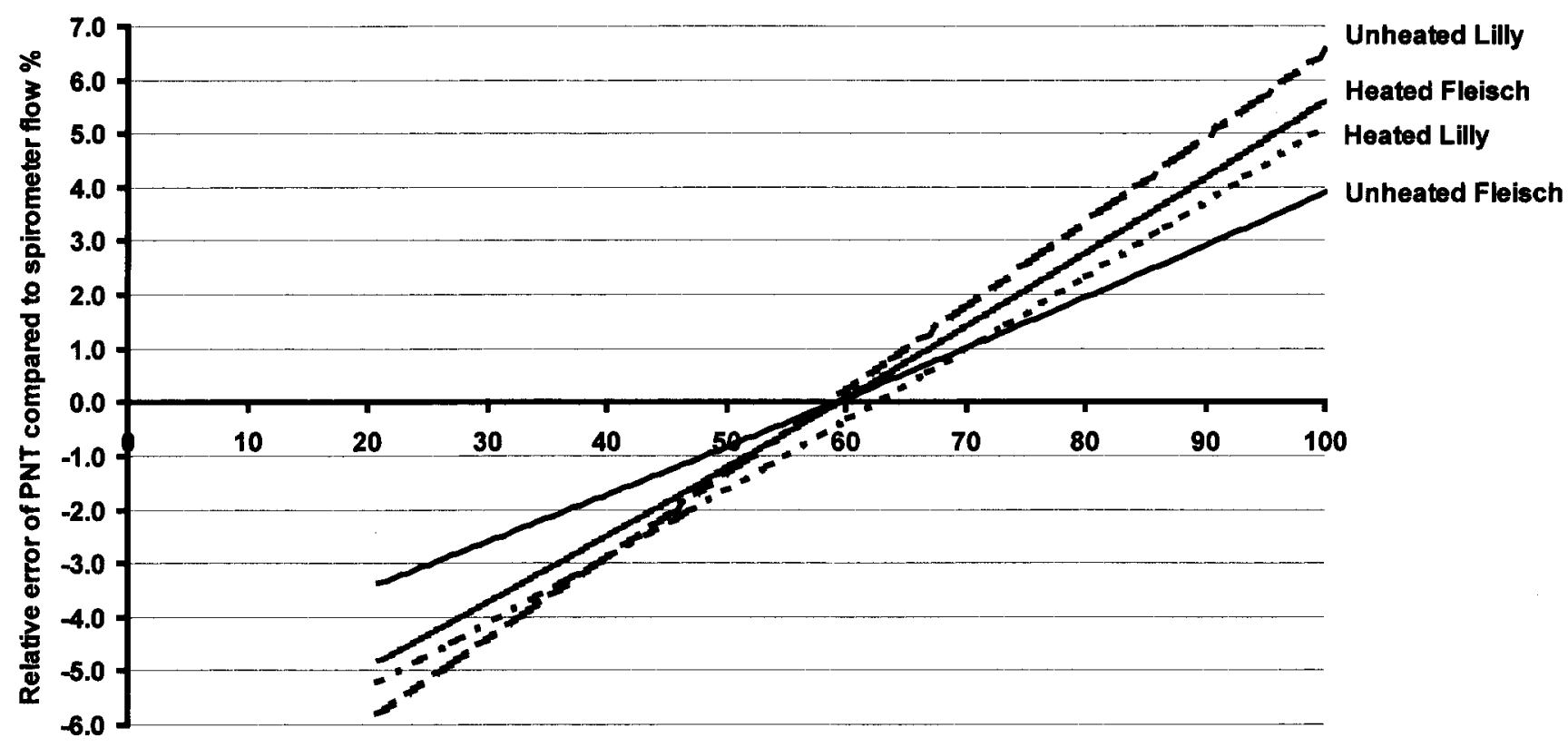

Oxygen concentration \%

Figure 2. Trends of relative measurement errors of the pneumotachometers $(P N T)$ at the calibrated flow rate $(3 \mathrm{~L} / \mathrm{min})$ at different oxygen concentrations. 


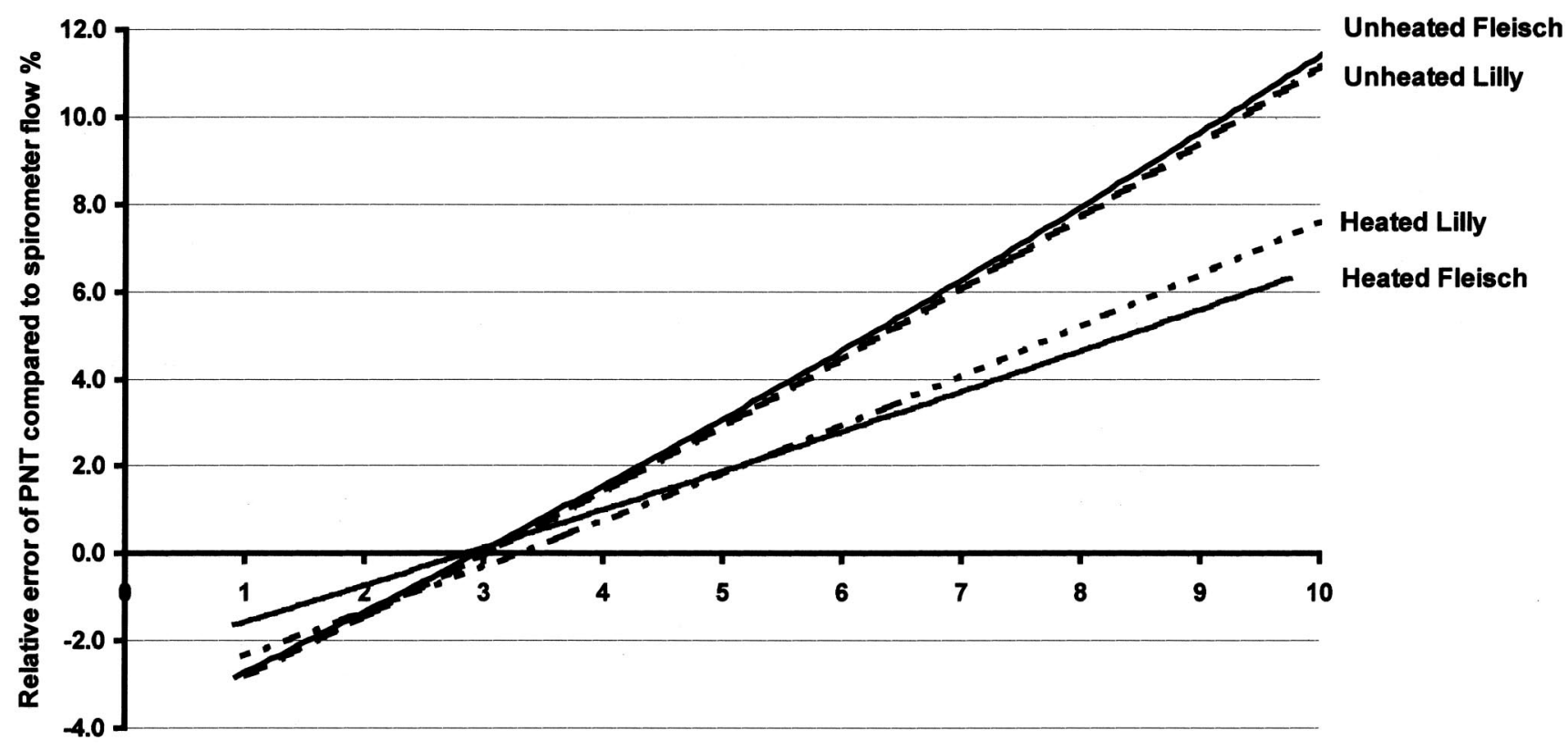

PNT flow rate L/min

Figure 3. Trends of relative measurement errors of the pneumotachometers $(P N T)$ at the calibrated oxygen concentration (60\%) at different flow rates.

Table 1. Multiple regression equations for each separate pneumotachometer

\begin{tabular}{llr}
\hline Pneumotachometer & \multicolumn{1}{c}{ Regression Equation } & $r^{2}$ \\
\hline Heated Fleisch & Flow $_{\mathrm{R}}{ }^{a}=1.10 \cdot \mathrm{Flow}_{\mathrm{M}}{ }^{b}-0.0013 \cdot \mathrm{Flow}_{\mathrm{M}} \cdot \mathrm{O}_{2} \%-0.086 \cdot\left(\mathrm{Flow}_{\mathrm{M}}\right)^{2}$ & $>.99$ \\
Unheated Fleisch & Flow $_{\mathrm{R}}=1.10 \cdot \mathrm{Flow}_{\mathrm{M}}-0.0009 \cdot \mathrm{Flow}_{\mathrm{M}} \cdot \mathrm{O}_{2} \%-0.015 \cdot\left(\mathrm{Flow}_{\mathrm{M}}\right)^{2}$ & $>.99$ \\
Heated Lilly & Flow $_{\mathrm{R}}=1.11 \cdot \mathrm{Flow}_{\mathrm{M}}-0.0013 \cdot \mathrm{Flow}_{\mathrm{M}} \cdot \mathrm{O}_{2} \%-0.011 \cdot\left(\mathrm{Flow}_{\mathrm{M}}\right)^{2}$ & $>.99$ \\
Unheated Lilly & Flow $_{\mathrm{R}}=1.14 \cdot \mathrm{Flow}_{\mathrm{M}}-0.0016 \cdot \mathrm{Flow}_{\mathrm{M}} \cdot \mathrm{O}_{2} \%-0.014 \cdot\left(\mathrm{Flow}_{\mathrm{M}}\right)^{2}$ & $>.99$ \\
\hline
\end{tabular}

${ }^{a}$ Flow $_{\text {REAL }}=$ spirometer flow $(\mathrm{L} / \mathrm{min}) ;{ }^{b}$ Flow $_{\text {MEASURED }}=$ pneumotachometer flow $(\mathrm{L} / \mathrm{min})$.

Table 2. Mean differences, limits of agreement and maximum error ranges in liters per minute according to Bland and Altman (18) analysis of the differences between the pneumotachometers and the spirometer

\begin{tabular}{lccc}
\hline Pneumotachometer & Mean & $\begin{array}{c}\text { Limits of } \\
\text { Agreement }\end{array}$ & $\begin{array}{c}\text { Maximum Error } \\
\text { Range (Mean) }\end{array}$ \\
\hline Before correction & & & \\
$\quad$ Heated Fleisch & -0.18 & $-0.83,0.46$ & $-1.09,0.40(1.5)$ \\
Unheated Fleisch & -0.20 & $-1.02,0.62$ & $-1.26,0.51(1.8)$ \\
Heated Lilly & -0.36 & $-1.33,0.61$ & $-1.08,0.17(1.3)$ \\
$\quad$ Unheated Lilly & -0.13 & $-1.01,0.74$ & $-1.28,0.58(1.9)$ \\
After correction & & & $-0.28,0.35(0.6)$ \\
$\quad$ Heated Fleisch & -0.01 & $-0.26,0.24$ & $-0.29,0.39(0.7)$ \\
Unheated Fleisch & -0.01 & $-0.34,0.31$ & $-0.51,0.37(0.9)$ \\
Heated Lilly & -0.04 & $-0.32,0.24$ & $-0.46,0.37(0.8)$ \\
$\quad$ Unheated Lilly & -0.02 & $-0.28,0.24$ & \\
\hline
\end{tabular}

ever, the actual gas temperature measured behind the heated pneumotachometer was also flow dependent. At lower flow rates, the gas had more time to warm up compared with higher flow rates. Hence, the temperature difference that we measured between low $(1 \mathrm{~L} / \mathrm{min})$ and high $(9 \mathrm{~L} / \mathrm{min})$ flow rates was $10^{\circ} \mathrm{C}$ for the heated Fleisch pneumotachometer $\left(40.0\right.$ to $\left.29.9^{\circ} \mathrm{C}\right)$. For the heated Lilly pneumotachometer, the maximum temperature difference was $5^{\circ} \mathrm{C}$ (30 to $24.9^{\circ} \mathrm{C}$ ). Maximal temperature differences of $10^{\circ} \mathrm{C}$ and $5^{\circ} \mathrm{C}$ cause maximal viscosity changes of $2.6 \%$ and $1.3 \%$, respectively (17). Temperature decreased at higher flow rates. Thus, leveling temperatures at all flows implies that the temperature at high flow rates should increase or the temperature at low flows should decrease. Increasing the temperature at high flows will increase gas viscosity and, thereby, the measurement error. The other possibility, decreasing temperature at low flow rates, results in the negative flow error to be increased. In both cases, the slope of the lines of both heated pneumotachometers will rise, approximating the ones of the unheated pneumotachometers.

Environmental changes during our experiments, such as changes in temperature, barometric pressure, and humidity outside the closed circuit, were negligible because changes were minimal and because calibration procedures were performed before each measurement procedure. The maximum changes in humidity would have caused a decrease in viscosity of $0.1 \%$. Barometric pressure changes would only give a measurable effect on viscosity when exceeding $500 \mathrm{kPa}$ (4), which it did not during our measurements. Because calibration was performed before each single measurement, the effect caused by a slightly different connection of the tubes to the pneumotachometers could be ignored. 
Heated Fleisch

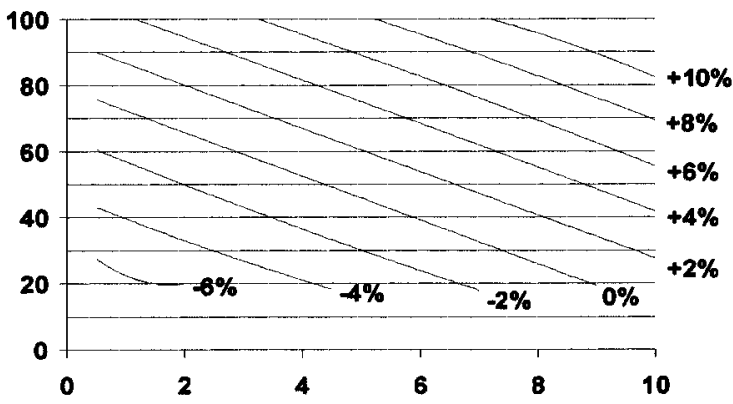

ㅇ
Heated Lilly

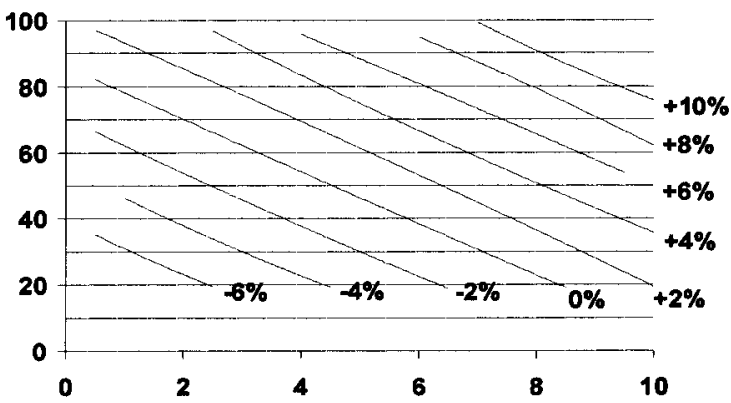

Unheated Fleisch

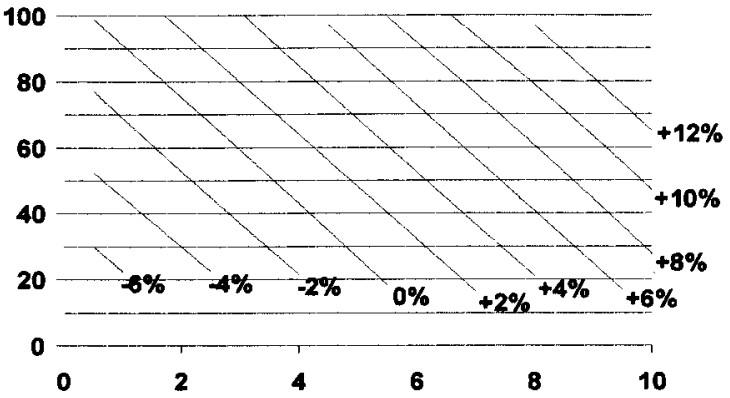

\section{Flow rate L/min}

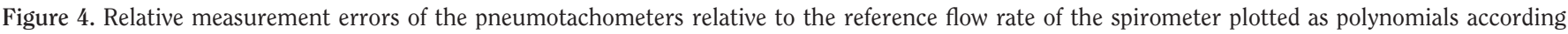

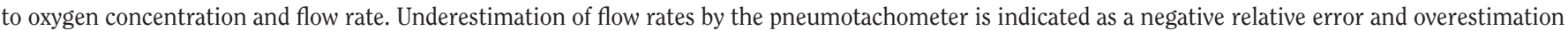
of flow rates as a positive relative error.

Furthermore, changes in temperature inside the spirometer during heating of the pneumotachometers could be neglected. After being heated by the pneumotachometer to temperatures of $>25^{\circ} \mathrm{C}$, air cooled down to room temperature by the time it reached the spirometer, which was $160 \mathrm{~cm}$ further in the circuit. The maximum temperature of $23.2^{\circ} \mathrm{C}$ measured at $80 \mathrm{~cm}$ behind the pneumotachometer, where the thermometer was located, proved that the air equilibrated quickly to room temperature $\left(22^{\circ} \mathrm{C}\right)$.

For example, at a neonatal intensive care unit, when the oxygen concentration in inspiratory air is increased, the viscosity of this gas mixture increases and thereby causes the pneumotachometers to overestimate flow rates (6). This effect was confirmed by our results, presenting a progressive measurement error at increasing oxygen concentrations. Because differences between pneumotachometers were relatively small and because they were not considered as the purpose of this study, a thorough discussion concerning the potential causes did not seem appropriate.

In equipment based on differential pressure, like pneumotachometers, turbulence can cause a considerable error, thereby overestimating flow rates. Frey et al. (19) indicated that the physical properties of most pneumotachometers usually cause a nonlinear relationship between the applied and measured signals. According to Yeh et al. (10), flowconductance characteristics of differential pressure pneumotachometers are nonlinear. Finucane et al. (20) observed a nonlinearity in screen pneumotachometers and in Fleisch-type pneumotachometers. Our data showed that flow errors in all pneumotachometers increased considerably when flow rates were progressively higher than calibration flow rate. Pneumotachometers underestimated at flow rates lower than calibration flows of 3 $\mathrm{L} / \mathrm{min}$. Although constant in the absolute way, this small error increased relatively at lower flow rates. Noise in the recorded signals probably caused the most important part of this measurement error. Although the pneumotachometers used should be linear within the flow range measured, nonlinearity of the pneumotachometers within this range was, in our opinion, the most plausible explanation for the error pattern that was found. Differences between pneumotachometers were again relatively small and were therefore not considered for discussion.

The correction factors, following the multiple regression equations for each heated and unheated pneumotachometer separately, reduced the measurement errors significantly in all pneumotachometers. Maximal error ranges were reduced by $>50 \%$ in most pneumotachometers. Peak flow rates in preterm neonates might exceed $6 \mathrm{~L} / \mathrm{min}$ in some cases. If we assume that flow rates in preterm infants varied between 0 and $6 \mathrm{~L} / \mathrm{min}$, according to our results, a measurement error of $\pm 9 \%$ could be expected when no correction was performed $( \pm 5 \%$ because of the oxygen effect and $\pm 4 \%$ caused by 


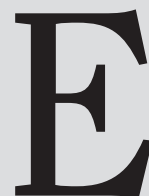

ffects of changes

in oxygen con-

centrations and

flow rates on neonatal pneu-

motachometers could be

considerably decreased by

the use of correction factors.

the flow-rate effect). After correction for oxygen and flow effects, a residual effect of $\pm 2 \%$ caused by variance in oxygen concentration and flow rate could be expected within a flow range of $0-6 \mathrm{~L} / \mathrm{min}$.

The pneumotachometers we tested are predominantly used in research settings to measure lung function (compliance, resistance, forced expiratory flow rates, etc.) in preterm infants. The role of lung function testing in improving ventilator adjustments and in diagnosis and prognosis of respiratory morbidity in neonates has been investigated increasingly during recent years. Consequently, lung function measures like respiratory resistance, which is highly flow dependent, will become more accurate after correction.

Some mechanical ventilators use comparable pneumotachometers. When the same pneumotachometers are used as described above, the built-in corrections for body temperature and pressure saturation might be extended with corrections for oxygen concentrations and flow rates based on our results. Integral application of the regression equations will be necessary for a reliable correction during conditions of changing flow.

Correction factors were based on measurements with dry gases at $22^{\circ} \mathrm{C}$, which were sufficiently constant during our measurement procedures. Because of their opposite effects on the viscosity of a gas, a simultaneous increase of humidity and temperature from dry air in the hospital circuit during calibration procedures (relative humidity approximating $0 \%$ at $22^{\circ} \mathrm{C}$ ) to a humidified and warmed environment (relative humidity of $95 \%$ at $37^{\circ} \mathrm{C}$ ) will result in a measurement error of approximately 2.9\% (4.1\% caused by the increase of temperature and $-1.2 \%$ caused by the increased humidity) (17).
This implicates that besides corrections for the effects of oxygen concentrations and flow rates, humidity and temperature effects should be corrected for when flow measurements are performed in the neonatal intensive care unit.

\section{CONCLUSIONS}

Our data showed that measurement errors in pneumotachometers were significantly affected by both flow rate and oxygen concentration. Therefore, it is necessary to calibrate with the actual oxygen concentrations and flow rates before starting a measurement in clinical or experimental settings. However, frequent calibration procedures during changes in gas composition in the clinical setting is often not practical (e.g., in case of increasing oxygen need in the neonate). For this reason, we calculated regression equations to correct flow readings during changing conditions, which significantly reduced the measurement errors. This means that after a calibration at 0 and 3 $\mathrm{L} / \mathrm{min}$ and $60 \%$ oxygen, reliable flow measurements can be achieved in the appropriate flow range and at all oxygen concentrations with the described neonatal pneumotachometers. In practice, quick corrections can be performed using polynomials, as shown in Figure 4. Further investigation is needed to extend the applicability of the correction factors in humidified and warmed conditions.

\section{ACKNOWLEDGMENTS}

We thank L. van Schelven for his helpful advice and E. Nieuwenhuis for her assistance during the measurements.

\section{REFERENCES}

1. Fletcher ME, Baraldi E, Steinbrugger B: Passive respiratory mechanics. In: Infant Respiratory Function Testing. Stocks J, Sly PD, Tepper RS, et al (Eds). New York, Wiley-Liss, 1996, pp 283-327

2. Blumenfeld W, Turney SZ, Cowley RA: Mathematical model for flow in the heated Fleisch pneumotachometer. Med Biol Eng Comput 1972; 11:546-551

3. Devabhaktuni VG, Torres A, Wilson S, et al: Effect of nitric oxide, perfluorocarbon, and heliox on minute volume measurement and ventilator volumes delivered. Crit Care Med 1999; 27:1603-1607

4. Foitzik B, Schmalisch G, Wauer RR: Einfluss Der Physikalischen Eigenschaften Des Atemgases Auf Die Pneumotachographische Ven- tilationsmessung Bei Neugeborenen. Biomed Tech (Berl) 1994; 39:85-92

5. Green M: The effects of changes in gas viscosity on measurement of gas flow rates and volumes by the pneumotachograph. Physiol Soc 1965; 19P-20P

6. Grenvik $\AA$, Hedstrand U, Sjögren H: Problems in pneumotachography. Acta Anaesthesiol Scand 1966; 10:147-155

7. Grenvik $\AA$, Hedstrand U: The reliability of pneumotachography in respirator ventilation. Acta Anaesthesiol Scand 1966; 10: 157-167

8. Roske K, Foitzik B, Wauer RR, et al: Accuracy of volume measurements in mechanically ventilated newborns: A comparative study of commercial devices. J Clin Monit Comput 1998; 14:413-420

9. Turney SZ, Blumenfeld W: Heated Fleisch pneumotachometer: A calibration procedure. J Appl Physiol 1973; 34:117-121

10. Yeh MP, Adams TD, Gardner RM, et al: Effect of $\mathrm{O}_{2}, \mathrm{~N}_{2}$ and $\mathrm{CO}_{2}$ composition on nonlinearity of Fleisch pneumotachograph characteristics. J Appl Physiol 1983; 56:1423-1425

11. von der Hardt H, Zywietz C: Reliability in pneumotachographic measurements. Respiration 1976; 33:416-424

12. Vaida P, Bargeton D, Guénard H: BTPS calibration of heated Fleisch pneumotachometer. Bull Eur Physiopathol Respir 1983; 19: 635-640

13. Wawersik J: Pneumotachographie, Anwendungsmöglichkeiten Und Methodische Grundlagen Im Rahmen Anaesthesiologischer Probleme Bei Säuglingen Und Kleinkindern. Anaesthesist 1965; 14:259-263

14. Frey U, Stocks J, Sly P, et al: Specifications for signal processing and data handling used for infant pulmonary function testing. Eur Respir J 2000; 16:1016-1022

15. Zock JP: Linearity and frequency response of Fleisch type pneumotachometers. Pflugers Arch 1981; 391:345-352

16. Kreit JW, Sciurba FC: The accuracy of pneumotachograph measurements during mechanical ventilation. Am J Crit Care Med 1996; 154:913-917

17. Bates JHT, Turner MJ, Lanteri CJ, et al: Measurement of flow and volume. In: Infant Respiratory Function Testing. Stocks J, Sly PD, Tepper RS, et al (Eds). New York, Wiley-Liss, 1996, pp 81-116

18. Bland JM, Altman DG: Statistical methods for assessing agreement between two methods of clinical measurement. Lancet 1986; 8:307-310

19. Frey U, Stocks J, Coates A, et al: Specifications for equipment used for infant pulmonary function testing. Eur Respir $J$ 2000; 16:731-740

20. Finucane KE, Egan BA, Dawson SV: Linearity and frequency response of pneumotachographs. J Appl Physiol 1972; 32:121-126 